\title{
Two morphologically and immunophenotypically distinct cell populations within a composite lymphoma arise from a common precursor
}

\author{
Harry Zhang • Hossein Salimnia • Gail Bentley • \\ Weimin Liu • Michele Phillips • Gerald L. Feldman • \\ Margarita Palutke
}

Received: 1 April 2011 /Accepted: 21 June 2011 /Published online: 8 July 2011

(C) Springer-Verlag 2011

\begin{abstract}
The term composite lymphoma defines a lymphoma consisting of two or more morphologically and immunophenotypically distinct lymphomas within the same lymph node or other organ. Recently, several molecular studies have shown that different components within a
\end{abstract}

H. Zhang $\cdot$ H. Salimnia $\cdot$ G. Bentley $\cdot$ W. Liu $\cdot$ G. L. Feldman M. Palutke

Department of Pathology and Laboratory Medicine,

Wayne State University School of Medicine,

Detroit, MI 48201, USA

\section{G. L. Feldman}

Department of Pediatrics and Center for Molecular Medicine and Genetics, Wayne State University School of Medicine,

Detroit, MI 48201, USA

H. Zhang $\cdot$ H. Salimnia $\cdot$ G. Bentley $\cdot$ W. Liu $\cdot$ M. Phillips $\cdot$

G. L. Feldman $\cdot$ M. Palutke

Detroit Medical Center University Laboratories,

Detroit Medical Center,

Detroit, MI 48201, USA

M. Palutke $(\bowtie)$

Core Hematology, DMC University Laboratories,

University Health Center,

4201 St. Antoine Blvd,

Detroit, MI 48201, USA

e-mail: mpalutke@dmc.org

Present Address:

H. Zhang

Department of Pathology, Oakwood Annapolis Hospital,

Wayne, MI, USA

Present Address:

W. Liu

Department of Pathology, McLaren Regional Medical Center,

Flint, MI, USA composite lymphoma may arise from a common clone. In contrast, there are also reports of biclonal cases of composite lymphoma. For this study, we identified five cases of composite lymphoma and analyzed them by various techniques to determine the clonality of the components. In four cases (1-4), a laser capture microdissection technique was used to collect separately each of the component lymphoma types. These were analyzed by polymerase chain reaction (PCR) to assess the rearrangement of the $\mathrm{J}$ segment of the immunoglobulin heavy chain gene $(\mathrm{JH})$. In all cases, gel electrophoresis demonstrated that the $\mathrm{JH}$ amplicons from each component were identical in size. DNA sequencing of the amplified JH region was successful in three of these four cases $(1,3$, and 4$)$, and the sequences of the $\mathrm{JH}$ regions of both components of each composite lymphoma were identical. Three of the composite lymphomas $(2,4$, and 5$)$ were also tested by a related approach: PCR of the variable region of the immunoglobulin heavy chain gene using primers that bind to framework regions 1,2 , and 3 , followed by capillary electrophoresis. The PCR amplicons from tissue containing a mixture of both components of the composite lymphomas gave one major peak in each of the three electropherograms for each lymphoma, indicating that only one clone of rearranged immunoglobulin was present despite the two distinct cellular morphologies. Additionally, fluorescence in situ hybridization in case one showed identical results in the two different cell types. Our results suggest that the two different components within each composite lymphoma represent a morphologically and immunophenotypically divergent differentiation of a common clone.

Keywords Composite lymphoma - Phenotypic divergence of monoclonal lymphoma 


\section{Introduction}

In the 1970s and early 1980s, while examining bone marrows for the staging of follicular lymphoma, grade 3 , we occasionally encountered lymphoid aggregates composed of small lymphocytes with no large cells present. At the time, we used the term "discordant morphology" to describe the different histology of the two lymphomas. We now think that many of these were early observations of what is currently called composite lymphomas. Kremer et al. [1] described 16 such cases and found that eight had a common clonal origin, four were biclonal, and four were chronic lymphocytic leukemia with Richter transformation.

The term composite lymphoma has been used to define a lymphoma consisting of two or more morphologically and/ or immunophenotypically distinct lymphomas within a lymph node or other organ $[2,3]$. A composite lymphoma may consist of two or more non-Hodgkin lymphomas, of a Hodgkin lymphoma and a non-Hodgkin lymphoma, or rarely, of a lymphoma of both B- and T-cell origins [2-5].

The diagnosis of composite lymphomas is largely based on morphologic and immunophenotypic characteristics, and it has been estimated that composite lymphomas may account for $1-5 \%$ of all malignant lymphomas [2]. Recent studies using molecular approaches suggest that composite Hodgkin and non-Hodgkin lymphoma originate from the same malignant clone [6-8]. The different cellular components within a composite lymphoma may result from a transformation to a higher grade lymphoma, which, unlike a Richter syndrome, is composed of cells with different immunophenotypes. However, Richter syndrome with different light chains has also been shown to be clonally related [9]. Composite lymphomas with cytogenetic or molecular evidence of biclonality have also been reported, especially composite B and T-cell lymphomas [10-18]. Recently, several morphologically and immunophenotypically different lymphomas have been shown to be clonally related $[1,6-8,19-21]$. For this investigation, we identified five archived cases of composite lymphoma based on morphologic and immunophenotypic criteria and applied molecular techniques to assess their clonality.

\section{Materials and methods}

Case selection

Five cases of composite lymphoma were identified either from one of the author's (MP) consultation files (cases 1, 3, and 5) or from the archives in the Department of Pathology and Laboratory Medicine at the Detroit Medical Center (cases 2 and 4). The diagnosis of a composite lymphoma was based on morphologic (Table 1) and immunophenotypic (Table 2) characteristics. Cytogenetic findings are in Table 3.

Immunohistochemical and flow cytometric analysis

Immunohistochemical studies were performed on formalinfixed, paraffin-embedded tissue sections using an avidinbiotin-peroxidase method with or without antigen retrieval. Flow cytometric analysis using a three-color flow cytometer (FACScan, Becton Dickinson, Mountain View, CA, USA) was performed in all five cases. The panel of antibodies used in this study is shown in Table 4. The monoclonal antibodies used in flow cytometric analysis were conjugated with either phycoerythrin or fluorescein isothiocyanate.

JH: Laser capture microdissection (LCM), polymerase chain reaction (PCR), electrophoresis, and DNA sequencing

To determine clonality, two different approaches were used. For the first, LCM of the two different components was performed [22]. Consensus primers for the $3^{\prime}$ ends of the $\mathrm{V}$ region and the $J$ region of the immunoglobulin heavy chain gene was used to amplify this portion of the rearranged heavy chain gene of each component of the composite as described previously [23]. Bands of identical sizes suggested clonality, which was confirmed by sequencing when possible. A complementary procedure for determination of the clonality of the three framework regions of the combined components was also used (see FR below)

LCM The two different components from cases 1-4 were microdissected and harvested from H\&E-stained tissue sections using a PixCell II laser capture microscope (Arcturus, Mountain View, CA, USA) as described previously $[8,22]$. The bone marrow biopsy block of case 3 was also available and subjected to molecular analysis. Case 5 could not be dissected by this technique due to the intermixed nature of the two components. Briefly, the tissue section was overlaid with a thermoplastic film mounted on an optically transparent cap. A laser pulse caused cells from the selected areas to adhere to the capture film. The capture film was incubated overnight in $0.5 \mathrm{ml}$ of digestion buffer containing $0.04 \%$ proteinase $\mathrm{K}, 10 \mathrm{mM}$ Tris- $\mathrm{HCl}, 1 \mathrm{mM}$ EDTA, and $1 \%$ tween 20 at $37^{\circ} \mathrm{C}$. The reaction was heated to $95^{\circ} \mathrm{C}$ for $8 \mathrm{~min}$ to inactivate proteinase $\mathrm{K}$ and centrifuged briefly. The supernatant was used directly as template for PCR amplification.

PCR Amplification (35 cycles) was performed in $25 \mu \mathrm{l}$ reactions containing 1.5 units Taq I polymerase (Applied Biosystems, Foster City, CA, USA) and $0.5 \mu$ lemplate 
Table 1 Clinical information and diagnoses

\begin{tabular}{lccll}
\hline Case no. & Age (years) & Sex & Biopsy/surgery site & Diagnosis (major/minor components (grade)) \\
\hline 1 & 58 & M & Spleen & SMZL(1)/follicular lymphoma(1) \\
2 & 47 & F & BM, ileum, cervical lymph node & Follicular lymphoma(1)/SLL \\
3 & 57 & F & BM, inguinal lymph node & Follicular lymphoma (3)/SLL \\
4 & 61 & F & BM, cervical lymph node & DLBCL (3)/SLL \\
5 & 65 & M & Inguinal lymph node & Follicular lymphoma (3)/SLL \\
\hline
\end{tabular}

$B M$ bone marrow, $S M Z L$ splenic marginal zone lymphoma, $S L L$ small cell lymphoma, $D L B C L$ diffuse large B cell lymphoma

DNA. Each cycle consisted of $95^{\circ} \mathrm{C}$ for $1 \mathrm{~min}, 64^{\circ} \mathrm{C}$ for $1 \mathrm{~min}$, and $72^{\circ} \mathrm{C}$ for $1 \mathrm{~min}$. Duplicate PCR reactions were set up. One reaction product was subjected to gel electrophoresis on $3.5 \%$ Metaphor ${ }^{\circledR}$ agarose (Lonza Rockland, Rockland, ME, USA) at $45 \mathrm{~V}$ for $16 \mathrm{~h}$, and UV transillumination of the ethidium bromide stained gel was used to analyze the size of the PCR products. The negative control is DNA from placental cells and the positive control consists of DNA from a wellcharacterized lymphoma cell line with a clonal immunoglobulin heavy chain gene rearrangement (InVivoScribe Technologies, San Diego, CA, USA) diluted in placental DNA.

Sequencing The other reaction product was cleaned up using a PCR purification kit (QiaGen, Germantown, MD, USA) according to manufacturer's protocol. The purified product was subjected to DNA sequencing on an ABI Prism 3,700 DNA Analyzer (Applied BioSystems) using the same JH primers as the initial PCR amplification. The sequence data were analyzed by the GCG Wisconsin sequence analysis package (Accelrys, San Diego, CA, USA).
PCR and capillary electrophoresis of FR amplicons

In a related approach, the clonality of three cases $(2,4$, and 5) of composite lymphoma was analyzed using three multiplex PCR reactions for each case, each reaction targeting one of three framework regions of the immunoglobulin heavy chain variable region (FR1, 2, and 3). PCR was followed by capillary electrophoresis as described previously [24]. Briefly, DNA was extracted from paraffinembedded tissue sections containing both components of the composite lymphoma. Multiplex PCR reactions were performed in three separate tubes using forward primers that anneal to one of the three FRs and a 5'-fluorescent labeled JH consensus primer. The JH consensus primer used as reverse primer for the FR1, FR2, and FR3 reactions was conjugated with blue, green, and red fluorophores, respectively. Each tube also contained a second set of primers that target the human beta-globin gene (HBB), which served as an amplification control. For each of the three multiplex assays, the primers for amplification of
Table 2 Major immunophenotypic differences of composite lymphoma cases
$B M$ bone marrow, $L N$ lymph node, $S M Z L$ splenic marginal zone lymphoma, $S L L$ small cell lymphoma, $D L B C L$ diffuse large B cell lymphoma, $F L$ follicular lymphoma

\begin{tabular}{|c|c|c|}
\hline Case No. & Organ & Immunophenotype \\
\hline 1 & Spleen & $\begin{array}{l}\text { SMZL: CD20+ CD5- CD10- BCL2 and BCL6- CyclinD1- kappa } \\
\text { FL: CD20+ CD10+ CD5- BCL2 and BCL6+CyclinD- }\end{array}$ \\
\hline \multirow[t]{2}{*}{2} & $\mathrm{LN}$ & $\begin{array}{l}\text { FL: CD20+ CD10+ CD5- CD23+ BCL2 and, BCL6+ lambda } \\
\text { SLL: CD20+ CD10- CD5+ CD23+ BCL2+ BCL6- lambda }\end{array}$ \\
\hline & $\begin{array}{r}\text { BM } \\
\text { Ileum }\end{array}$ & $\begin{array}{l}\text { SLL: CD20+ CD10- CD5+ lambda } \\
\text { FL: CD20+ CD10+ CD5- lambda }\end{array}$ \\
\hline \multirow[t]{2}{*}{3} & $\mathrm{LN}$ & $\begin{array}{l}\text { FL: CD20+ CD10+ CD5- CD23+ BCL2+ BCL6+ CD79a+ } \\
\text { SLL: D20+ CD10- CD5+CD23+ BCL2+ BCL6- CD79a+ }\end{array}$ \\
\hline & $\mathrm{BM}$ & SLL: CD20+ CD10- CD5+, no L chain expression \\
\hline \multirow[t]{2}{*}{4} & $\mathrm{LN}$ & $\begin{array}{l}\text { DLBCL: CD20+ CD10+ CD5-, CD23-, BCL2+ BCL6+ CyclinD1-lambda } \\
\text { SLL: CD20+ CD10- CD5, CD23- BCL2+ BCL6- CyclinD1- kappa }\end{array}$ \\
\hline & $\mathrm{BM}$ & SLL: CD20+ CD10- CD5- CD23- BCL2- BCL6- kappa \\
\hline \multirow[t]{2}{*}{5} & $\mathrm{LN}$ & $\begin{array}{l}\text { FL: CD20+ CD10+ CD5- BCL2+ BCL6+ kappa } \\
\text { SLL CD20+ CD10- CD5- BCL2- BCL6+ kappa }\end{array}$ \\
\hline & $\mathrm{BM}$ & Not involved \\
\hline
\end{tabular}


Table 3 Cytogenetic findings

\begin{tabular}{lll}
\hline Case no. & Organ & Cytogenetics \\
\hline 1 & Spleen & $46, \mathrm{XY}, \mathrm{add}(17)(\mathrm{p} 13)$ marginal zone component \\
& & No $t(14 ; 18)$ by FISH; p53 deletion by FISH in follicular area \\
2 & LN & FL: $46, \mathrm{XX}$, add $(6)(\mathrm{q} 21), \mathrm{t}(14 ; 18)(\mathrm{q} 32 ; \mathrm{q} 21)$ \\
3 & LN & FL: No $t(14 ; 18)$ by FISH \\
4 & LN & DLBCL: $50, \mathrm{XX}, \operatorname{der}(1 ; 22)(\mathrm{q} 10 ; \mathrm{q} 10) x 2,+2, \mathrm{t}(3 ; 14)(\mathrm{q} 27 ; \mathrm{q} 32)+7, \operatorname{der}(21 ; 22)(\mathrm{q} 10 ; \mathrm{q} 10) \times 2,+\mathrm{mar}[20]$ \\
& BM & BCL6 negative $($ poor preparation, very few cells to examine $)$ \\
& LN & No cytogenetics performed \\
\hline
\end{tabular}

HBB were designed to produce an amplicon slightly larger than the expected size of FR amplicon in that reaction mix to check for the quality/integrity of the template DNA extracted from the paraffin-embedded tissue sections. The amplified products were fractionated using capillary electrophoresis and detected by the fluorescence emitted by the dyes conjugated to the primers for the different target regions. The electropherograms were collected by the ABI 3,100 Genetic Analyzer and analyzed with dye matrices and sizing parameters using ABI GeneMapper ID software (Applied Biosystems). If no clonal population had been present, a broad distribution of polyclonal (background) products would have been seen. If the PCR product contains a specific, over-represented rearrangement (clonal population), a unique amplified product appears as a sharp peak against the polyclonal background distribution. Two separate clones would be expected to yield two distinct peaks. The size ranges expected from each PCR product are as follows: FR1 (blue channel), 310-360 bp; FR2 (green channel), 250-295 bp; FR3 (red channel), 100-170 bp; HBB gene (control, black channel), peaks at 358,317 , and $168 \mathrm{bp}$, respectively.

\section{Results}

Clinical Summary, Histologic and Immunophenotypic Analysis. This information is summarized in Tables 1 and 3 and cytogenetic studies in Table 6 .

Case 1 A 58-year-old man presented with lymphocytosis and splenomegaly. Splenectomy was performed. Multiple sections of the spleen showed expansion of the white pulp with effacement of the germinal centers by a population of
Table 4 Antibodies used in immunophenotyping
IHC Immunohistochemistry, flow flowcytometry

\begin{tabular}{lll}
\hline Antibody & Company & Comment \\
\hline CD3 & Vector-Novocastra Laboratories, Burlingame, CA, USA & IHC \\
CD5 & Vector-Novocastra Laboratories, Burlingame, CA, USA & IHC \\
CD10 & Vector-Novocastra Laboratories, Burlingame, CA, USA & IHC \\
CD20 & DAKO, Carpinteria, CA, USA & IHC \\
CD23 & DAKO, Carpinteria, CA, USA & IHC \\
Kappa & DAKO, Carpinteria, CA, USA & IHC \\
Lambda & DAKO, Carpinteria, CA, USA & IHC \\
cyclin D1 & Ventana Medical, Tuson, CA, USA & IHC \\
BCL2 & Ventana Medical, Tuson, CA, USA & IHC \\
BCL6 & Ventana Medical, Tuson, CA, USA & IHC \\
Ki-67 & Ventana Medical, Tuson, CA, USA & IHC \\
CD2 & Becton-Dickinson, San Jose, CA, USA & Flow \\
CD3 & Becton-Dickinson, San Jose, CA, USA & Flow \\
CD5 & Becton-Dickinson, San Jose, CA, USA & Flow \\
CD10 & Becton-Dickinson, San Jose, CA, USA & Flow \\
CD19 & Becton-Dickinson, San Jose, CA, USA & Flow \\
CD20 & Becton-Dickinson, San Jose, CA, USA & Flow \\
CD23 & Becton-Dickinson, San Jose, CA, USA & Flow \\
Kappa & Becton-Dickinson, San Jose, CA, USA & Flow \\
Lambda & Becton-Dickinson, San Jose, CA, USA & Flow \\
FMC7 & Beckman-Coulter, Miami, FL, USA & Flow \\
\hline
\end{tabular}


Fig. 1 Composite splenic marginal zone lymphoma and follicular lymphoma (case 1). A Peripheral lymphocytosis with villous lymphocytes $(\times 100)$. B Microscopic focus of follicular lymphoma in a background of marginal zone lymphoma ( $\mathrm{H} \& \mathrm{E}$, $\times 4)$. C Marginal zone lymphoma consisting predominantly of small lymphocytes with scattered transformed immunoblasts $(H \& E, \times 40)$. D Follicular lymphoma consisting predominantly of small cleaved centrocytes with rare large centroblasts (grade 1; H\&E, ×40). E-H Immunostains for CD3, CD20, CD10 and BCL2 highlighting two components of the composite lymphoma $(\times 10)$ : SMZL with CD20+CD10- weak BCL2+; FL with strong CD20+ CD10+BCL2+
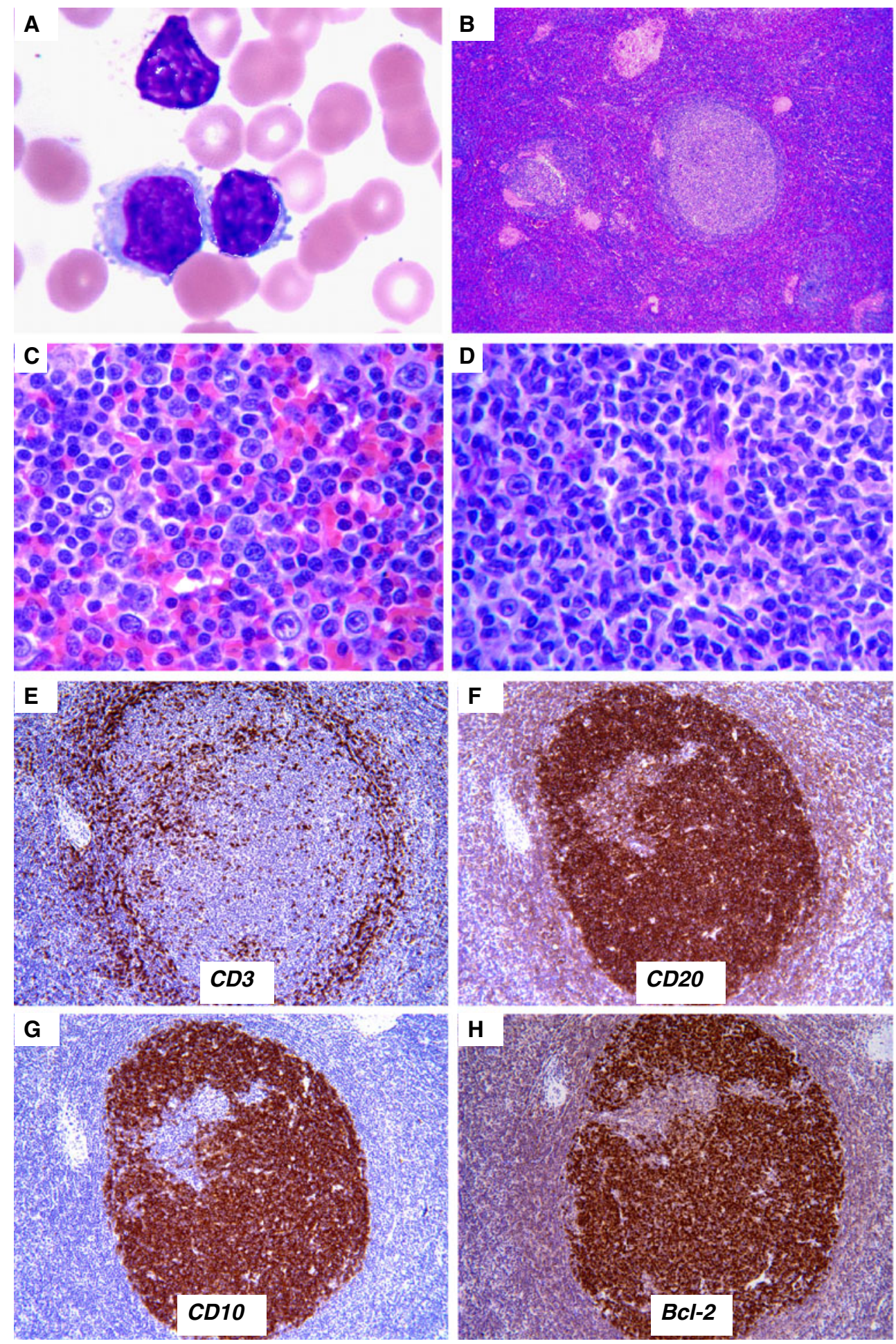

small lymphocytes with a moderate amount of pale cytoplasm, round nuclei, and dispersed chromatin. Scattered transformed large lymphocytes with prominent nucleoli (immunoblasts) were present. The lymphocytes were positive for $\mathrm{CD} 20$ and BCL2, and negative for CD5 and CD10 (Fig. 1). Flow cytometric analysis identified a population of monoclonal B-cells with the following immunophenotype:
CD19+, CD20+, CD5-, CD10-, CD23-, and FMC7+ with monotypic kappa light chain expression. These findings support a diagnosis of splenic marginal zone lymphoma. In addition, a few sections contained several neoplastic follicles with morphologic features characteristic of a grade 1 follicular lymphoma. By immunostaining, the neoplastic lymphoid cells in the follicles were positive for CD20, 
CD10, BCL2, and BCL6. Cyclin D1 was negative in both components. Cytogenetics and fluorescence in situ hybridization (FISH) showed a p53 deletion in both the marginal zone and follicular components. There was no $t(14 ; 18)$.

Case 2 A 47-year-old woman was found by CT scan to have a mass in the terminal ileum and retroperitoneal lymphadenopathy. A biopsy of the mass in the terminal ileum was diagnosed as follicular lymphoma, grade one, with an immunophenotypic profile of CD19+, CD20+, $\mathrm{CD} 10+, \mathrm{CD} 5-$, and monotypic lambda light chain expression. A staging biopsy on the bone marrow showed interstitial and paratrabecular lymphoid aggregates of small lymphocytes consistent with bone marrow involvement by lymphoma. However, flow cytometric analysis on the bone marrow identified a population of monoclonal B-cells coexpressing CD19, CD20, CD5, lambda but negative for CD10. These cells appeared to represent a different lymphoma, either mantle cell lymphoma or a small lymphocytic lymphoma. A biopsy of the left supraclavicular lymph node was performed, which revealed two distinct components of neoplastic lymphoid cells. The primary component was a grade one follicular lymphoma. A secondary component of small lymphocytic lymphoma was also identified. Flow cytometric analysis of the lymph node demonstrated two distinct populations: one composed of monoclonal B-cells expressing CD10 (similar to the follicular lymphoma in the ileum) and a second composed of monoclonal B-cells expressing CD5 (similar to the small lymphocytic lymphoma in the marrow).

Case 3 A 57-year-old woman presented with left inguinal lymphadenopathy. The excised lymph node showed complete architectural effacement by a nodular and diffuse proliferation of predominantly large lymphoid cells with vesicular nuclei and prominent nucleoli. At the periphery of the lymph node, and infiltrating into the perinodal adipose tissue, were sheets of small lymphocytes. By immunostain, the large lymphoid cells were positive for CD20, CD79a, CD10, BCL2, and
BCL6 with a MIB-1 labeling index of $30 \%$, while the small lymphoid cells were positive for CD20, CD79a, CD23, and CD5. A diagnosis of composite follicular lymphoma, grade 3 with a small component of diffuse large B cell lymphoma (5\%) and small lymphocytic lymphoma was rendered (Fig. 2). Flow cytometric analysis on a staging bone marrow aspirate and biopsy identified an 18\% B cell population expressing CD19, CD20, and CD5 without light chain expression, but CD10 negative. FISH for $t(14 ; 18)$ performed on the lymph node was negative.

Case 4 A 61-year-old woman presented with generalized lymphadenopathy and B symptoms (night sweats and weight loss). A right cervical lymph node biopsy showed a diffuse proliferation of large lymphoid cells with pleomorphic nuclei, vesicular chromatin, and prominent nucleoli. The lymphoid cells were CD20+, CD10+, CD5-, BCL6 +, BCL2 dim+, with a MIB-1 labeling index of $80 \%$. In addition, at the periphery of the lymph node and in the capsule, there was a second component of small lymphocytic cells, which were positive for CD20 and negative for CD5 and CD10, BCL2+, and BCL6-. By flow cytometry of the neck mass, a population of $\mathrm{CD} 20+, \mathrm{CD} 5-, \mathrm{CD} 10^{-}$, and kappa + as well as a second population of $\mathrm{CD} 20+$, $\mathrm{CD} 10+, \mathrm{C} 5-$, and lambda+ were identified. The bone marrow was involved by small lymphocytic lymphoma (CD5-, CD10-, and kappa+). This case was diagnosed as a composite lymphoma consisting of a diffuse large B-cell lymphoma and a small lymphocytic lymphoma.

Case 5 A 65-year-old man had an enlarged inguinal lymph node. An excisional biopsy revealed an architecture effaced by neoplastic follicles composed of small centrocytes and large centroblasts $(>15 / \mathrm{hpf}$, grade 3$)$. There also was an expanded interfollicular region composed mostly of small lymphocytes with scattered large immunoblasts. The cells in the follicles were positive for CD20, CD10, BCL2, and BCL6. The small cells in the interfollicular areas were negative for CD5, CD10, and BCL2 but positive for CD20
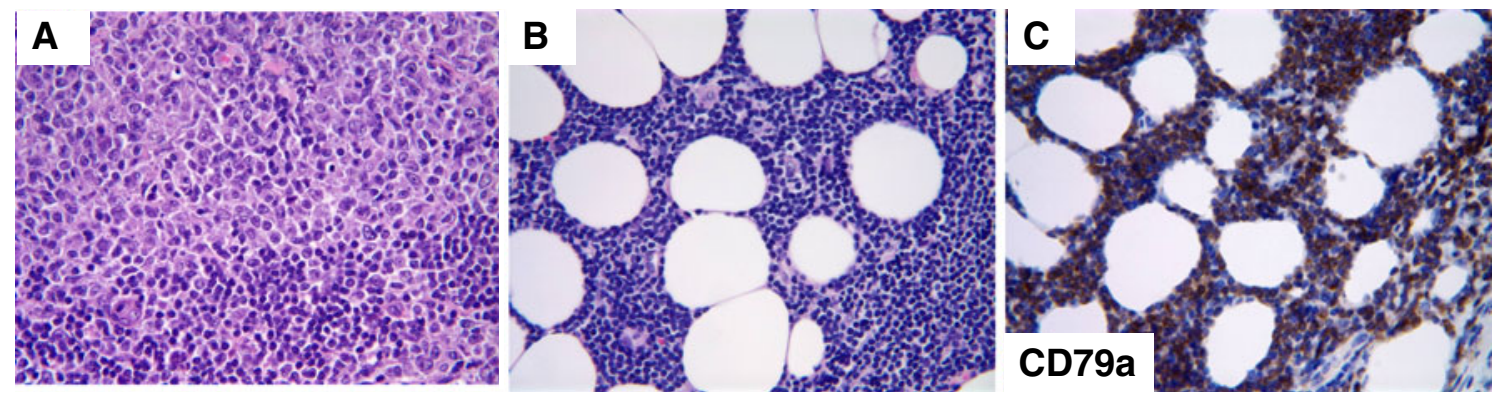

Fig. 2 Composite lymphoma in lymph node. Follicular lymphoma, grade 3A and small lymphocytic lymphoma (case 3); A follicular lymphoma, B small lymphocytic infiltrate in perinodal fat, $\mathbf{C}$ small lymphocytes in perinodal fat are CD79a positive B cells 


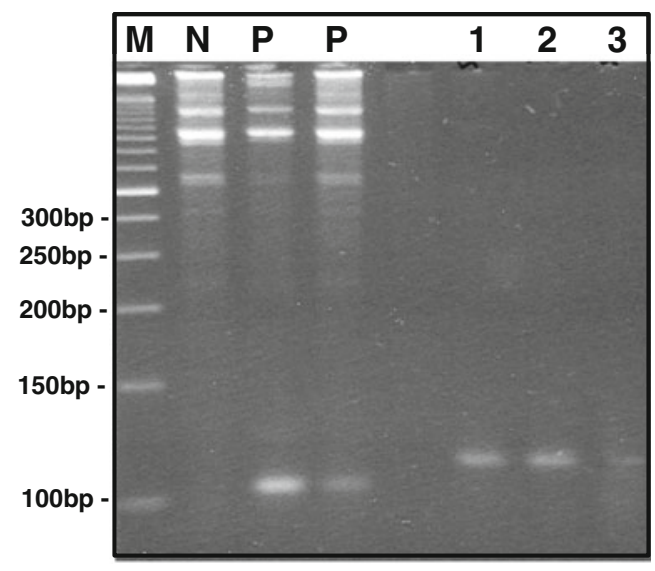

Fig. 3 PCR amplication of JH from each component of the composite lymphoma (case 3) followed by electrophoresis fractionation on $3.5 \%$ metaphor agarose. After separation by laser capture microdissection (LCM) of the lymph node, each separate component as well as the bone marrow was subjected to PCR and agarose gel electrophoresis. $M$ Molecular marker, a 50-bp DNA ladder with the lowest band at $100 \mathrm{bp} ; N$ negative control, placental DNA; $P$ positive control, DNA from a lymphoma cell line diluted in placental DNA; 1 FL, 2 SLL, 3 bone marrow. The highmolecular weight bands in the controls are presumed to result from nonspecific amplification of high-molecular weight DNA, as the controls were not subjected to fixation, embedding, sectioning and LCM, and their DNA was not degraded in the process

and BCL6. Flow cytometric analysis showed two distinct CD20+ kappa-restricted lymphocyte populations: the CD10+ large lymphoma cells, and CD10- small lymphoma cells. The bone marrow was not involved. This case was diagnosed as composite follicular lymphoma grade three and small lymphocytic lymphoma.

\section{Molecular analysis}

\section{$J H$}

In cases $1-4$, LCM was used to harvest separately cells from each component of the composite lymphoma. The bone marrow biopsy block of case 3 was also available and subjected to JH analysis. PCR amplification of the DNA extracted from each component was performed separately and they were run side-by-side on a gel with a sizing ladder and the positive and negative controls. The negative control, placental tissue, shows no clonal bands of rearranged immunoglobulin genes. The positive control is DNA from a known lymphoma cell line diluted with the placental DNA. It exhibits a prominent monoclonal band. There are nonspecific, high-molecular weight bands in the negative and positive controls that do not appear in the PCR reactions using DNA template extracted from microdissected tissue. This is probably because the DNA from the fixed, embedded, and microdissected tissue is more degraded and does not contain large-size template DNA. In each of the four cases analyzed by this technique, gel electrophoresis of the PCR products derived from each of the two components of the composite lymphoma revealed single bands of identical size, suggesting that the two components were originally derived from the same clone. The bands from each case differed in size from those of the other patients' specimens and ranged from $<100$ to $>150 \mathrm{bp}$. Figure 3 shows the agarose gel electrophoresis of $\mathrm{JH}$ regions in case 3. Bands in lanes 1 and 2 are from the two components derived from the lymph node. The band in lane 3 is derived from the malignant small lymphocytes of the bone marrow paraffin block of this patient. The bone marrow cells were extracted and analyzed in an identical fashion to the components of the lymph node and exhibited a monoclonal band of the same molecular weight as the lymph node components.

DNA sequence analysis of the amplified $\mathrm{JH}$ regions from three of the four cases (cases 1, 3, and 4) revealed identical sequences in the two distinct malignant cell populations. DNA sequencing could not be performed in case 2 because one of the sequencing reactions failed and there was inadequate specimen to repeat it after the FR analysis had been completed. The results from the molecular analysis of the $\mathrm{JH}$ regions of all four cases are presented in Table 4.

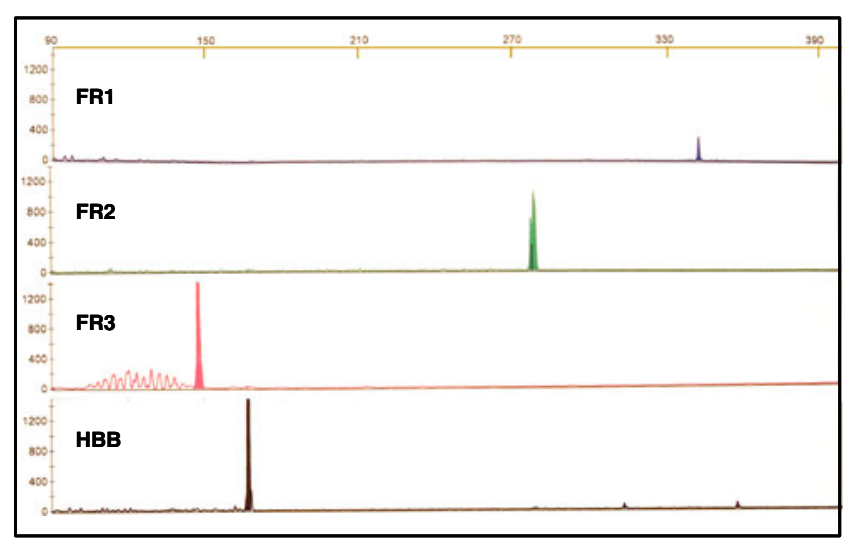

Fig. 4 Capillary electrophoregrams of PCR-amplified composite follicular lymphoma and small lymphocytic lymphoma (case 5) using primers for the FR regions. Three multiplex PCR reactions were performed using primers targeting the three $\mathrm{VH}$ framework regions (FR). The conjugated $\mathrm{JH}$ consensus primer used as the reverse primer in each multiplex PCR was labeled differently (blue, green, and red flurophores for FR1, FR2, and FR3, respectively). Different primers for the human beta-globin gene were also added to each multiplex PCR. The primers were chosen so that the beta-globin amplicon was close to the same size as the expected FR product so that it could best serve as an amplification control. The amplified products were fractionated using capillary electrophoresis and detected through differential fluorescence emission resulting from the fluorophore conjugated to the $\mathrm{JH}$ consensus primer for the different targeted regions. Single peaks of $343 \mathrm{bp}$ (blue), $279 \mathrm{bp}$ (green), and $148 \mathrm{bp}$ (red) of DNA fragments were detected corresponding to FR1, FR2, and FR3 of the VH. The black peak (168 bp) is amplicon of the human betaglobin gene that was used as internal control for FR3 reaction. The peaks of HBB for reaction FR2 (317 bp) and FR1 (358 bp) are not shown 
Table 5 PCR and sequencing of $\mathrm{JH}$

$S M Z L$ splenic marginal zone lymphoma, $F L$ follicular lymphoma, SLL small lymphocytic lymphoma, $D L B C L$ diffuse large B cell lymphoma

\begin{tabular}{llll}
\hline Case no. & Diagnosis & PCR. products & DNA sequencing \\
\hline 1 & SMZL/FL & Clonal, same size (about $165 \mathrm{bp})$ & Identical \\
2 & FL/SLL & Clonal, same size (about $90 \mathrm{bp}$ ) & Not done \\
3 & FL/SLL & Clonal, same size (about $115 \mathrm{bp})$ & Identical \\
4 & DLBCL/SLL & Clonal, same size (about $120 \mathrm{bp})$ & Identical \\
\hline
\end{tabular}

$F R$

Three cases (2, 4, and 5) were subjected to analysis of $\mathrm{VH}$ rearrangement by performing PCR with primers targeting the different framework regions followed by capillary electrophoresis. In this approach, DNA was extracted from paraffin-embedded tissue sections containing both malignant lymphoid components, followed by three multiplex PCR reactions, each targeting one of the three framework regions (FR1, 2, and 3) of the immunoglobulin heavy chain variable region. The PCR products were analyzed by capillary electrophoresis. In case 2, single peaks of 117 , 258 , and 322 bp of PCR products were present in the electropherograms. In case 4, single peaks of 321 and $256 \mathrm{bp}$ of PCR products were present with FR1 and FR2 primers. A double peak of 124 and $127 \mathrm{bp}$ was present with FR3 primer. The 127-bp peak was very small compared to the stronger 124-bp peak. In case 5, single peaks of 343, 278, and 148 bp corresponding to the FR1, FR2, and FR3 regions were identified in the electropherograms (Fig. 4 and Table 5).

\section{Discussion}

Composite lymphomas consist of two morphologically and phenotypically distinct lymphomas in the same tissue. Most of the reported cases have been a combination of classical Hodgkin lymphoma with B cell lymphoma; however, there

Table 6 PCR and capillary electrophoresis of FR

\begin{tabular}{|c|c|c|c|c|}
\hline \multirow[t]{2}{*}{ Case no. } & \multirow[t]{2}{*}{ Diagnosis } & \multicolumn{3}{|c|}{ Electropherogram } \\
\hline & & FR1 (bp) & FR2 (bp) & FR3 (bp) \\
\hline 2 & FL/SLL & 322 & 258 & 117 \\
\hline 4 & FL/SLL & 321 & 356 & 124 and $127^{\circ}$ \\
\hline 5 & FL/SLL & 343 & 279 & 148 \\
\hline
\end{tabular}

FL follicular lymphoma, SLL small lymphocytic lymphoma

${ }^{a}$ Case 4 exhibited three major bands: FR1 with 321 bp, FR2 with $356 \mathrm{bp}$, and FR3 with 127 base pairs. The FR3 product also showed a minority component (about 3\% of the total) that was three base pairs smaller than the major 127 -bp peak are reported cases large cell lymphomas with small cell lymphomas of various types. A report of $\mathrm{T}$ lymphoblastic leukemia/lymphoma and diffuse large B cell lymphoma was recently published. Some of these have been reported to be monoclonal [1, 6, 19-21], while others appear to be biclonal [10-18]. Analysis of clonality is important for the understanding of the origins of composite lymphomas. Whether clonality impacts patient outcomes remains to be determined.

Using several different molecular techniques, we studied the clonality of five composite lymphomas from our archives: all five of them appear to be monoclonal. Although case 5 may represent a downregulated small lymphocytic component of a follicular lymphoma grade 3. In three bone marrows studied by flow cytometry, the small lymphocytic lymphoma was found to be immunophenotypically the same as that component in the lymph node. In case 3 this was confirmed by molecular analysis. In addition, the malignant cells in the bone marrow of case 3 had a monoclonal band of the same size and sequence as the components of the composite lymphomas from the lymph nodes.

Although it had been our original intention to perform the same analyses on all five cases, this proved impossible because the amount of tissue available was limited. Thus, we were unable to perform the FR analysis on cases 1 and 3 after finishing the $\mathrm{JH}$ analysis. We were also unable to repeat the LCM on case 2 when one of the sequencing reactions failed, because the remainder of the specimen had already been used for the $\mathrm{VH}$ rearrangement (FR) analysis. Case 5 was not amenable to LCM, because the two cellular components were too intermingled. The size of the amplicons of the $\mathrm{JH}$ regions and/or of products terminating in the FR regions is currently used by several commercial reference laboratories to demonstrate clonality. The JH study revealed that the different components of each of the four composite lymphomas analyzed had identically sized JH regions. Sequencing of the JH regions of three of these revealed that the nucleic acid sequences of both components were identical (Table 5).

The FR rearrangement analysis is complementary to the JH amplification. For this study, tissue containing both components of cases 2, 4, and 5 were analyzed 
without separating the components. Cases 1 and 4 had inadequate specimen remaining at the end of the $\mathrm{JH}$ analysis and so FR PCR could not be performed. Multiplex PCR/capillary electrophoresis of tissue containing both components of the composite lymphoma cases 2 and 5, targeting each of the three framework regions, showed only one band, suggesting monoclonality. Case 4 showed single bands for FR1 and FR2. The FR3 reaction exhibited a double peak consisting of major band of 124 base pairs and a very small second peak (estimated at approximately 3\%) of 127 base pairs. The cause or importance of this finding is not known but it could be the result of changes in the hypervariable region or somatic mutation, which could eventually lead to the evolution of a third member of the composite that would be molecularly distinct from the other two. "Slippage" of the polymerase, which may occur in regions of repeating bases, has also been noted to cause such changes [25]. Overall, our results suggest that different lymphoid components within each of these five composite lymphomas are clonally related and that the two distinct subpopulations represent morphological and immunophenotypical divergence from a common precursor. In composite lymphomas consisting of both low- and high-grade components such as cases 4 and 5 (both of which consist of a low grade B-cell lymphoma and a grade three follicular lymphoma), the high-grade component may represent a clonal evolution of the low-grade component, analogous to Ritcher syndrome (transformation of chronic lymphocytic leukemia into a high-grade B-cell lymphoma).

The study is limited by several factors. The cases were sent in consultation by outside physicians or hospitals, and treatment and outcome data is unfortunately not available. The quantity of specimen available was limited and only two cases had adequate specimen available for all the tests. The selection of tests which were performed first on each specimen was a matter of convenience. Thus, when the tissue ran out, the testing that remained unperformed was variable. In addition, all of the tissue used for molecular studies was fixed and embedded. This is not optimal as fixation may affect the integrity and the quality of the DNA for PCR amplification. However, fixation usually results in failure to amplify and might cause an elevated background, but seems unlikely to result in a false impression of clonality. Our data support the hypothesis that all five of the composite lymphomas reported in this study are of clonal origin.

Further molecular evaluations of monoclonal composite lymphomas in different stages of the disease will improve our understanding about the development and evolution of the different components within a composite lymphoma.
Acknowledgments We thank Marilynn Fairfax, M.D., Ph.D. for editorial assistance and Jennifer K. Sanks, MT, from Molecular Diagnostics Laboratory at University of Michigan Hospitals for her excellent technical support.

Conflicts of interest The authors declare that they have no conflict of interest.

\section{References}

1. Kremer M, Spitzer M, Mandl-Weber S, Stecker K, Schmidt B, Hofler H, Quintanilla-Martinez L, Fend F (2003) Discordant bone marrow involvement in diffuse large B cell lymphoma: comparative molecular analysis reveals a heterogeneous group of disorders. Lab Invest 83(1):107-114

2. Kim H (1993) Composite lymphoma and related disorders. Am J Clin Pathol 4:445-451

3. Strickler JG, Amsden TW, Kurtin PJ (1992) Small B-cell lymphoid neoplasm with co-existing T-cell lymphomas. Am J Clin Pathol 98(4):424-429

4. Ioachim HL, Ratech H (2002) Composite lymphoma in Ioachim's lymph node pathology, 3rd edn. Lippincott Williams and Wilkins, Philadelphia, PA, pp 436-439

5. Kaleem Z, McGuire MH, Caracioni AC, Leonard RL, Pathan MH, Lessmann EA, Chan WC (2005) Composite B-cell and T-cell nonHodgkin lymphoma if the tibia. Am J Clin Pathol 123(2):215-221

6. Brauninger A, Hansmann ML, Strickler JG, Dummer R, Burg G, Rajewsky K, Kuppers R (1999) Identification of common germinal-center B-cell precursors in two patients with both Hodgkin's disease and non-Hodgkin's lymphoma. N Engl J Med 340(16):1239-1247

7. Kuppers R, Sousa AB, Baur AS, Strickler JG, Rajewsky K, Hausmann ML (2001) Common germinal-center B-cell origin of the malignant cells in two composite lymphomas, involving classical Hodgkin's disease and either follicular lymphoma or BCLL. Mol Med 7(5):285-292

8. Bayerl MG, Bentley G, Bellan C, Leoncini L, Ehmann WC, Palutke M (2004) Lacunar and Reed-Sternberg-like cells in follicular lymphomas are clonally related to the centrocytic and centroblastic cells as demonstrated by laser capture microdissection. Am J Clin Pathol 122(6):858-864

9. Nakamine H, Masth AS, Sanger WG, Wickert RS, Mitchell DW, Armitage JO, Weisenburger DD (1992) Richter's syndrome with different immunoglobulin light chain types: molecular and cytogenetic features indicate a common clonal origin. Am J Clin Pathol 97(5):656-663

10. Wlodarska I, Delabie J, De-Wolf-Peeters C, Mecucci C, Stul M, Werhoef G, Cassiman JJ, Van den Berghe H (1993) T-cell lymphoma developing in Hodgkin's disease: evidence for two clones. J Pathol 170(3):239-248

11. Fend F, Quintanilla-Martinez L, Kumar S, Beaty NW, Blum L, Sorbara L, Jaffe ES, Raffeld M (1999) Composite low grade Bcell lymphomas with two immunophenotypically distinct cell populations are true biclonal lymphomas. A molecular analysis using laser capture microdissection. Am J Path 154(6):18571866

12. Caleo A, Sanchez-Aguilera A, Rodriguez S, Dotor AM, Beltran L, de Larrinoa AF, Menarguea FJ, Piris MA, Garcia JF (2003) Composite Hodgkin lymphoma and mantle cell lymphoma: two clonally unrelated tumors. Am J Surg Pathol 27(12):1577-1580

13. Zamo A, Zanotti R, Lestani M, Ott G, Katzenberger T, Scarpa A, Pizzolo G, Menestrina F, Chilosi M (2006) Molecular characterization of composite mantle cell and follicular lymphoma. Virchows Arch 448(5):639-643 
14. Niino D, Ohsaki K, Arakawa F, Watanabe J, Kimura Y, Kiyasu J, Takeuchi M, Miyoshi H, Yoshida M, Sugita Y, Ohshima K, Okamura T (2011) Composite T lymphoblastic leukemia/lymphoma and diffuse large B cell lymphoma: case report. Pathol Int 61:363368

15. Roullet M, Martinez D, Ma L, Halpern Fowler M, McPhail E, Judkins A, Arber D, Baag A (2010) Coexisting follicular and mantle cell lymphoma with each having an in situ component. Am J Clin Pathol 133:584-591

16. Deville JP, Heimann P, El Housni H, Boutriaux M, Jeronnes A, Remmelink M, Lasudry J, Pradler O, Kentos A (2007) Biclonal low grade B cell lymphoma confirmed by both flow cytometry and karyotypic analysis in spite of a normal kappa/lambda Ig light chain ratio. Am J Hematol 82:473-480

17. Lefebvre C, Fabre B, Vettier C, Rabin L, Florin A, Wang J, Gressin R, Jacob M-C, Callanan M, Leroux D (2007) Composite splenic marginal zone lymphoma and mantle cell lymphoma arising from 2 independent B cell clones. Hum Pathol 38:660667, DipMolBiol

18. Rodig S, Healey B, Pinkus G, Kuo F, Dal Cin P, Kutok J (2006) Mantle cell lymphoma arising within primary nodal marginal zone lymphoma: a unique presentation of two uncommon B-cell lymphoproliferative disorders. Cancer Genet Cytogenet 171 (1):44-51

19. diSibio G, Gabor EP, Lopategui J, Sabath DE, Alsabeh R, Cole JM (2010) Large cell transformation of a composite lymphoma. Exp Mol Pathol 89(3):260-267
20. Visco C, Hoeller S, Malik JT, Xu-Monette ZY, Wiggins ML, Liu J, Sanger WG, Liu Z, Chang J, Ranheim EA, Gradowski JF, Serrano S, Wang HY, Liu Q, Dave S, Olsen B, Gascoyne RD, Campo E, Swerdlow SH, Chan WC, Tzankov A, Young KH (2011) Molecular characteristics of mantle cell lymphoma presenting with clonal plasma cell component. Am J Surg Pathol 35(2):177189

21. Tsang P, Pan L, Cesarman E, Tepler J, Knoweles DM (1999) A distinctive composite lymphoma consisting of clonally related mantle cell lymphoma and follicular center lymphoma. Hum Pathol 30(8):988-992

22. Emmert-Buck MR, Bonner RF, Smith PD, Chuaqui R, Zhuang Z, Goldstein SR, Weiss RA, Liotta LA (1996) Laser capture microdissection. Science 274(5289):998-1001

23. Trainor KJ, Brisco MJ, Wan JH, Neoh S, Grist S, Morley AA (1991) Gene rearrangement in B- and T-lymphoproliferative disease detected by the polymerase chain reaction. Blood 78 (1):192-196

24. Greiner TC, Gascoyne RD, Anderson ME, Kingma DW, Adomat SA, Said J, Jaffe ES (1996) Nodular lymphocyte-predominant Hodgkin's disease associated with large-cell lymphoma: analysis of Ig gene rearrangement by $\mathrm{JH}$ polymerase chain reaction. Blood 88(2):657-666

25. Fairfax MR, Salimnia H (2010) Quantitative PCR: an introduction in handbook of molecular diagnostics. WW Grody, RM Nakamura, FL Kiechle, and C Strom (eds). New York: Academic Press, pp 3-14 